\title{
Erratum to: In silico study of binding motifs in squalene synthase enzyme of secondary metabolic pathway of solanaceae
}

\author{
Sanchita - Garima Singh - Ashok Sharma
}

Published online: 31 August 2014

(C) Springer Science+Business Media Dordrecht 2014

\section{Erratum to: Mol Biol Rep}

\section{DOI 10.1007/s11033-014-3603-x}

Following section of the original version of the article unfortunately contains errors. The corrected version is given below.

1. The manuscript title, "In silico study of binding motifs in squalene synthase enzyme of secondary metabolic pathway solanaceae family" may be read as "In silico study of binding motifs in squalene synthase enzyme of secondary metabolic pathway of solanaceae".

2. Under result section, subheading motif analysis, lines 2, 3, 4, 5, 6, 7, 8 and 9 "(Fig. 2). All protein sequence of SQS reported two conserved motifs viz., motif 1
"YCHYVAGLVGLGLSKL" which was 16 residue long and motif 2 "MGLFLQKTNIIRDYLEDINEIPKSRMFWP", which was 29 residue long. In positions of motifs lied between 170 and 186 for motif 1 and 205 and 234 for motif 2. Only in the case of $N$. tabacum the length of motif 2 varied. These motif sequences were previously reported in other plants with several residues substitution [22, 23]." may be treated as deleted.

3. Under subheading "Molecular docking" the line, "FPP was found to bind with two residues LYS ${ }^{223}$ and VAL 221263261 of the motif 2 (Fig. 6a).” may be read as "FPP was found to bind with two residues LYS ${ }^{223}$ and VAL ${ }^{221}$ of the motif 2 (Fig. 6a)."
The online version of the original article can be found under doi: 10.1007/s11033-014-3603-x.

Sanchita $(\bowtie) \cdot$ G. Singh $\cdot$ A. Sharma

Biotechnology Division, CSIR-Central Institute of Medicinal and Aromatic Plants, Post Office CIMAP,

Lucknow 226015, India

e-mail: 0804sanchita@gmail.com 